Original Article

\title{
Comparison of dynamic balance ability in healthy university students according to foot shape
}

\author{
In Hyouk Hyong, PT, PhD ${ }^{1)}$ Jong Ho Kang, PT, $\mathrm{PhD}^{2)^{*}}$ \\ 1) Department of Physical Therapy, Shinsung University, Republic of Korea \\ 2) Department of Physical Therapy, College of Health Sciences, Catholic University of Pusan: \\ 57 Oryundae-ro, Geumjeong-gu, Busan 609-757, Republic of Korea
}

\begin{abstract}
Purpose] This study aimed to compare dynamic balance ability according to foot shape, defined as normal, pronated, or supinated on the basis of the height of the medial arch. [Subjects] In this study, 14 subjects for the pronated foot group, 14 for the supinated foot group, and 14 for the normal foot group were selected from among 162 healthy university students by using the navicular drop test proposed by Brody. To measure dynamic balance ability, a star excursion balance test (SEBT) was conducted for each group, in which a cross-shaped line and lines at $45^{\circ}$ in eight directions were drawn on the floor. In this study, only three directions were used, namely anterior, posterolateral, and posteromedial. The mean of the SEBT was calculated by measuring three times for each group, and the values were standardized using the following equation: measured value/leg length $\times 100$. [Results] No significant differences in dynamic balance ability were found between the normal, pronated, and supinated foot groups. [Conclusion] No significant differences in dynamic balance ability according to the foot shape were found among the healthy university students with normal, pronated, and supinated feet.

Key words: Dynamic balance, Navicular drop (ND) test, Pronated foot
\end{abstract}

(This article was submitted Oct. 15, 2015, and was accepted Nov. 19, 2015)

\section{INTRODUCTION}

The feet require proper weight distribution during many body motions such as those for the maintenance of static balance and gait. Therefore, the feet have impact-absorbing structures, such as transverse, medial longitudinal, and lateral arches, to distribute the body weight during both static and dynamic states. In general, an abnormally low medial longitudinal arched foot is called pes planus or flatfoot ${ }^{1)}$, which is divided into rigid and flexible pes planus ${ }^{2}$. Pes planus has been reported to cause abnormal functions of the tendon sheath of the tibialis posterior, including dynamic imbalance ${ }^{3)}$, pain ${ }^{4}$, joint damage $^{5)}$, and even stress fractures ${ }^{6}$.

The foot is divided into three types according to the height of the medial transverse arch, and Cote et al. ${ }^{7)}$ classified these as pronated, normal, and supinated by using the navicular drop (ND) test. Pronated feet are caused by reduced height of the medial longitudinal arch, reducing the weight distribution during static and dynamic states, thus causing foot pain and an overall functional reduction of the lower extremities, as previously reported ${ }^{6}$.

Studies on static ability according to foot type have also been conducted ${ }^{5,8}$. Depending on the foot type, the ground contact area differs. Studies on the center of pressure (COP) and sway have been conducted based on this difference. The feet play a role in controlling balance, thus providing static stability. Hertel et al. ${ }^{8)}$ reported that the COP speed of pronated feet was increased when compared to that of normal feet because of the reduced static stability of the pronated feet. Cote et al. ${ }^{7)}$ emphasized that dynamic balance differed depending on the shape of the foot in specific directions, especially in the anterior

\footnotetext{
*Corresponding author. Jong Ho Kang (E-mail: swithun@cup.ac.kr)

(C)2016 The Society of Physical Therapy Science. Published by IPEC Inc.

This is an open-access article distributed under the terms of the Creative Commons Attribution Non-Commercial No Derivatives (by-nc-nd) License $<$ http://creativecommons.org/licenses/by-nc-nd/4.0/>.
} 
direction. However, in one of their studies, Cote et al. ${ }^{7)}$ reported no significant differences in the center of balance or postural sway between pronated and normal feet, implying that the foot shape (pronated or normal) is not related to static stability.

The feet have dual functions with regard to static stability while standing and during dynamic mobility in gait. Many studies have already reported on static stability; therefore, the present study compared dynamic balance ability between pronated, normal, and supinated feet with regard to gait in order to determine whether dynamic balance ability differs according to foot type.

\section{SUBJECTS AND METHODS}

In this study, 14 subjects each for the pronated, supinated, and normal foot groups were selected from among 162 healthy university students by using the ND test proposed by Brody ${ }^{9}$. The mean age, weight, and height of the subjects were 20.9 years, $61.2 \mathrm{~kg}$, and $165.5 \mathrm{~cm}$, respectively. No significant differences in these characteristics were found among the groups. This study was approved by the Bioethics Committee of the Catholic University of Pusan (CUPIRB-2015-026).

In order to classify foot type, the ND test ${ }^{9)}$ was used, in which the subjects were seated comfortably in a chair, with their feet on the ground, to mark the furthest protruding part of the medial navicular tubercle. Then, the distance from the ground to the marked navicular tubercle was measured with a plastic ruler. This distance was also measured while the subjects were in the standing position, under weight-bearing conditions. By comparing the measured values between the sitting and standing positions, the subjects were classified into normal, pronated, and supinated foot groups if the difference was within a range of 5 to $9 \mathrm{~mm}$, more than $10 \mathrm{~mm}$, or less than $4 \mathrm{~mm}$, respectively ${ }^{9}$. Each of the measurements was conducted three times, and the mean value was calculated. The dominant foot was the foot used for the measurements.

To measure dynamic balance ability, a star excursion balance test (SEBT) was conducted for each group, because of its high reliability (intraclass correlation coefficient, $0.88-0.96)^{10}$ ). For the SEBT, a cross-shaped line was drawn on the floor, with additional lines drawn $45^{\circ}$ in eight directions. In this study, only three directions were used (anterior, posterolateral, and posteromedial), according to the study by Hyong ${ }^{11)}$. The measurements were conducted while the subjects set the heels of their dominant feet at the center point and stretched the feet in the anterior direction as much as possible while maintaining balance. The point where the big toe ended was marked. The posterolateral and posteromedial directions were measured in the same way. Each subject's measurements were taken three times, and the mean value was calculated for each group. In order to minimize errors due to differences in leg length between the subjects, the values were standardized using the formula: measured value/leg length $\times 100$. For the leg length measurements, the distance between the anterior superior iliac spine of the medial malleolus and the tubercle of the shin was measured while the subject was in the supine position. Statistical analysis was conducted using SPSS version 12.0, while one-way analysis of variance was used to compare dynamic balance ability among the three groups. The significance level was set to 0.05 .

\section{RESULTS}

The SEBT results obtained by comparing dynamic balance ability among the normal, pronated, and supinated foot groups showed no significant differences in any of the three directions (anterior, posterolateral, and posteromedial; Table 1).

\section{DISCUSSION}

The purpose of this study was to compare dynamic balance ability according to foot shape, which was classified according to the height of the medial arch of the foot. In this study, no significant differences in dynamic balance ability were found among the normal, pronated, and supinated foot groups. This result is consistent with the results of a study conducted by Kim et al. ${ }^{5}$, in which the feet were divided into a normal foot group (5-9 $\mathrm{mm}$ of ND, resting calcaneal stance position [RCSP] within $2^{\circ}$ of inversion and eversion) and a flexible pes planus group ( $>10 \mathrm{~mm}$ of ND and $>4^{\circ}$ of eversion in the RCSP) using the ND test ${ }^{9)}$ and the RCSP test (RCST) ${ }^{12}$. Dynamic balance ability was compared between the two groups by using the Y balance test ${ }^{13)}$. No significant difference in dynamic balance ability was found between the normal foot and flexible pes planus groups. In addition, Kim et al. ${ }^{5)}$ speculated that this result was due to the compensation action of postural adaptation while conducting the balance test, which was caused by muscular adaptation due to external factors such as visual integration, auditory, somatosensory, and other proprioceptive systems, as well as for biomechanical reasons. The muscles that are

Table 1. Star excursion balance test results according to foot type $(n=42)$

\begin{tabular}{lccc}
\hline & Normal foot & Pronation foot & Supination foot \\
\hline Anterior (\%) & $99.0 \pm 68.5$ & $94.6 \pm 7.1$ & $98.4 \pm 8.8$ \\
Posterolateral (\%) & $67.3 \pm 10.8$ & $65.2 \pm 15.9$ & $70.4 \pm 14.9$ \\
Posteromedial (\%) & $79.4 \pm 9.7$ & $79.9 \pm 10.6$ & $80.2 \pm 14.2$ \\
\hline
\end{tabular}


involved in the compensation and adaptation to postural balance during dynamic motion such as gait are the tibialis anterior and peroneus longus muscles ${ }^{14}$. Thus, Kim et al. ${ }^{5}$ reported that despite the differences in foot shape, no significant difference in dynamic balance abilities were found because of the above mentioned muscular compensation actions.

In their study, Cote et al. ${ }^{7)}$ classified the subjects into normal, pronated, and supinated foot groups using the ND test ${ }^{9}$ and compared the dynamic balance abilities of the groups in eight directions using the SEBT. Among the eight directions, the anterolateral, posteromedial, and medial directions showed no differences, whereas the anterior direction showed a significant difference among the three groups. The lateral, posterior, and posterolateral directions showed significant differences between the pronated and supinated foot groups, while the anteromedial direction showed a significant difference between the normal and pronated foot groups. Moreover, Cote et al. ${ }^{7}$ explained the abovementioned results by suggesting that a supinated foot had more pressure on the lateral side of the foot, thereby limiting stability, and a medially deviated pronated foot increased mobility, thereby increasing dynamic balance ability, especially in the anterior direction. However, their study did not provide sufficient comparisons and analyses in all the directions.

Olmsted et al. ${ }^{15)}$ compared dynamic balance ability between individuals who had no ankle joint damage and those who had chronic ankle joint instability in eight directions using the SEBT. They reported that the dynamic balance abilities of the individuals who had ankle joint instability were reduced in all eight directions. On the contrary, they also reported that individuals who had pronated or supinated feet had increased dynamic balance abilities in specific directions, when compared to normal persons who had no ankle joint instability. They suggested that these results showed that foot shape affects the range of motion of the joints through the action of the neuromuscular system and special dynamics while stretching the foot in a specific direction. However, the reduction in dynamic balance ability experienced by individuals with chronic ankle joint instability can be due to muscle weakness around the ankles and the instability of the articular surface. In addition, decreases in the proprioception and increases in the dynamic balance in specific directions in the pronated or supinated foot require explanations about the interactions between the muscles and joints, as well as the precise mechanical rationale.

The present study conducted experiments with young university students who had no previous ankle joint injuries and showed no changes in their dynamic balance abilities according to three different types of feet. This result was likely due to the compensation adaptation of the muscles surrounding the ankle joint to external factors that affect balance, such as the visual, auditory, and somatosensory systems, despite the foot shape differences based on the height of the medial transverse arch, as explained by Kim et al. ${ }^{5}$ ) Furthermore, the surrounding tarsal bones that are connected with the navicular bone, which is the center of the increase or decrease in the medial transverse arch of the foot, are the cuneiform in the anterior direction and the talus in the posterior direction. The reduction in the dynamic balance ability adjustment is believed to be due to the relative lack of connectivity with the talocrural and subtalar articulations that are responsible for foot balance. For future research, studies on the compensation adaptations of the surrounding muscles and mechanisms underlying the interactions among the joints in the feet are needed.

\section{REFERENCES}

1) Kitaoka HB, Luo ZP, An KN: Three-dimensional analysis of flatfoot deformity: cadaver study. Foot Ankle Int, 1998, 19: 447-451. [Medline] [CrossRef]

2) Flemister AS, Neville CG, Houck J: The relationship between ankle, hindfoot, and forefoot position and posterior tibial muscle excursion. Foot Ankle Int, 2007, 28: 448-455. [Medline] [CrossRef]

3) Tome J, Nawoczenski DA, Flemister A, et al.: Comparison of foot kinematics between subjects with posterior tibialis tendon dysfunction and healthy controls. J Orthop Sports Phys Ther, 2006, 36: 635-644. [Medline] [CrossRef]

4) Lakstein D, Fridman T, Ziv YB, et al.: Prevalence of anterior knee pain and pes planus in Israel defense force recruits. Mil Med, 2010, 175: 855-857. [Medline] [CrossRef]

5) Kim JA, Lim OB, Yi CH: Difference in static and dynamic stability between flexible flatfeet and neutral feet. Gait Posture, 2015, 41: 546-550. [Medline] [CrossRef]

6) Yoon KS, Park SD: The effects of ankle mobilization and active stretching on the difference of weight-bearing distribution, low back pain and flexibility in pronated-foots subjects. J Exerc Rehabil, 2013, 9: 292-297. [Medline] [CrossRef]

7) Cote KP, Brunet ME, Gansneder BM, et al.: Effects of pronated and supinated foot postures on static and dynamic postural stability. J Athl Train, 2005, 40: 41-46. [Medline]

8) Hertel J, Gay MR, Denegar CR: Differences in postural control during single-leg stance among healthy individuals with different foot types. J Athl Train, 2002, 37: 129-132. [Medline]

9) Brody DM: Techniques in the evaluation and treatment of the injured runner. Orthop Clin North Am, 1982, 13: 541558. [Medline]

10) Hyong IH, Kim JH: Test of intrarater and interrater reliability for the star excursion balance test. J Phys Ther Sci, 2014, 
26: 1139-1141. [Medline] [CrossRef]

11) Hyong IH: The effects on dynamic balance of dual-tasking using smartphone functions. J Phys Ther Sci, 2015, 27: 527-529. [Medline] [CrossRef]

12) Jay RM, Schoenhaus HD, Seymour C, et al.: The Dynamic Stabilizing Innersole System (DSIS): the management of hyperpronation in children. J Foot Ankle Surg, 1995, 34: 124-131. [Medline] [CrossRef]

13) Fitzgerald D, Trakarnratanakul N, Smyth B, et al.: Effects of a wobble board-based therapeutic exergaming system for balance training on dynamic postural stability and intrinsic motivation levels. J Orthop Sports Phys Ther, 2010, 40: 11-19. [Medline] [CrossRef]

14) Mulligan EP, Cook PG: Effect of plantar intrinsic muscle training on medial longitudinal arch morphology and dynamic function. Man Ther, 2013, 18: 425-430. [Medline] [CrossRef]

15) Olmsted LC, Carcia CR, Hertel J, et al.: Efficacy of the Star Excursion Balance Tests in determining reach deficits in subject with chronic ankle instability. J Athl Train, 2002, 37: 501-506. [Medline] 